University of Wollongong

Research Online

Faculty of Business - Papers (Archive)

Faculty of Business and Law

$1-1-2014$

University teaching with a disability: student learnings beyond the curriculum

Lynnaire Sheridan

University of Wollongong, lynnaire.sheridan@otago.ac.nz

Suzanne Kotevski

University of Wollongong, suzannek@uow.edu.au

Follow this and additional works at: https://ro.uow.edu.au/buspapers

Part of the Business Commons

Research Online is the open access institutional repository for the University of Wollongong. For further information contact the UOW Library: research-pubs@uow.edu.au 


\title{
University teaching with a disability: student learnings beyond the curriculum
}

\begin{abstract}
This research examines the learning experience of university students who were tutored by a teacher with quadriplegia mixed type cerebral palsy. It was inspired by Pritchard's [2010. "Disabled People as Culturally Relevant Teachers." Journal of Social Inclusion 1 (1): 43-51] argument that the presence of people with a disability in the classroom is important as these teachers deliver both content and generate 'other' learnings. This study examines what was different about the learning experience and what additional learnings may have occurred because of the students' interaction with a tutor with a disability. It begins to explore what educational scaffolding may be needed to facilitate and maximise student learning in this scenario both in the classroom and online learning environment with a tutor with a disability affecting physical movement and verbal communication. It seeks to advocate for the potential role of people with a disability in academia.
\end{abstract}

\section{Keywords}

beyond, student, university, teaching, learnings, disability, curriculum

Disciplines

Business

\section{Publication Details}

Sheridan, L. \& Kotevski, S. (2014). University teaching with a disability: student learnings beyond the curriculum. International Journal of Inclusive Education, 18 (11), 1162-1171. 
University teaching with disability: Student learnings beyond the curriculum

Lynnaire Sheridan and Suzanne Kotevski

School of Management and Marketing, Faculty of Business, University of Wollongong

PO Box 2055, Tarrawanna, NSW 2518

lynnaire@uow.edu.au

+61242213654 


\section{Abstract}

This research examines the learning experience of university students who were tutored by a teacher with quadriplegia mixed type cerebral palsy. It was inspired by Pritchard's argument that the presence of people with a disability in the classroom is important as these teachers deliver both content and generate 'other' learnings (Pritchard 2010). This study examines what was different about the learning experience and what additional learnings may have occurred because of the students' interaction with a tutor with a disability. It begins to explore what educational scaffolding may be needed to facilitate and maximise student learning in this scenario both in the classroom and online learning environment with a tutor with quadriplegia mixed type cerebral palsy has affected physical movement and verbal communication. It seeks to advocate for the potential role of people with a disability in academia.

\section{Keywords}

quadriplegia mixed type cerebral palsy

Disability

Higher education

Blended learning 


\section{Introduction}

In 2010 the Faculty of Business at the University of Wollongong, Australia, internally advertised for an administrative officer to support the Faculty's work-integrated learning program - an elective subject in the Bachelor of Commerce which combines an industry placement with academic assessment of workplace-based learning . An administrator with quadriplegia mixed type cerebral palsy applied; however, it was mutually decided, due to the physicality of that role, that she was unsuitable for that role. The academic coordinator for the program, however, then considered that this well qualified staff member (with a Masters in Commerce) could instead undertake a teaching, rather than administrative, role in the subject affiliated with this work-integrated learning program. An authentic, and logistically possible, learning interaction between students and this person with a disability had presented itself because the subject had limited face-to-face lectures and a strong online component. Moreover, the subject coordinator believed that the pro-active stance of the University of Wollongong towards fostering diversity in the staff and student population (beyond compliance with the State of New South Wales Anti-Discrimination Act 1997 and State of New South Wales Disabilities Services Act of 1993) should inform the student experience. In this case business students, who otherwise would not be formally exposed to disability studies, could achieve experiential learnings on diversity at university concurrent with their work-integrated learning in industry.

The idea that this staff member could undertake a teaching role was raised with relevant academic and administrative leaders. The initial reaction, while positive, was to classify the role as 'marking', essentially evaluating assessments via the online system. After deeper discussion of the tasks involved, which innately involve more mentoring than marking, it was determined that the person with a disability would be a tutor and able to engage more fully in the subject delivery. So the opportunity was created to engage a person 
with quadriplegia mixed type cerebral palsy in teaching facilitated principally via new technologies.

The tutor describes her disability as quadriplegia mixed type cerebral palsy Where quadriplegia, cerebral palsy is “... a persistent but not unchanging disorder of movement and posture due to a defect or lesion of the developing brain.” (Centre for Developmental Disability Health Victoria 2005). Quadriplegia mixed type cerebral palsy refers to someone with cerebral palsy who experiences stiffness and a floppy state occurring in all four limbs accompanied by uncontrolled movements. In this case, the tutor uses a wheelchair, has limited verbal communication and no hand use. She relies on a head pointer to type on a computer and operates her wheelchair via a chin control. Assistance is required to transition her from being mobile to her computer-based activities.

In this context, it will now be understood that the academic subject coordinator recognised that some scaffolding for students to learn about disability and diversity would be required. It was decided that this could be best achieved by the tutor participating in two face-to-face lectures to provide a context for the students who would subsequently interact with the tutor in an online environment. At the first lecture each semester, the tutor is introduced to students and, in both lectures, activities she has designed are facilitated via a digital story and PowerPoint slides incorporating voice output technologies are used by the subject lecturer (unfortunately 'live' interaction technologies are still not easily available in the physical classroom environment). Moreover, while the coordinator understood the practicality of online teaching for the tutor, she also felt that a visual presence in the classroom was important - that the tutor be seen and heard (albeit using pre-prepared voiced materials) - but also for the tutor to hear student discussions in real time outside of online assessments and engage in the shared learning experience which occurs in the classroom. 
While the original motivation was to create a career opportunity for an academically qualified person with a disability, it was soon clear that researching this experience had the potential to more broadly inform people with a disability, and their work supervisors, about how teaching can be achieved by people with a physical disability for effective student learning. As the literature review began, it was clear that this was an unusual scenario - there was not a rich academic base from which to draw. There was, however, one interesting paper by Pritchard in 2010 which expanded the realms of the current study by suggesting that students might not only learn content from a teacher with a disability but also achieve additional learnings about disability, life and themselves (Pritchard 2010). Moreover, Shannon et al. (2009) and subsequently Hayashi and May (2011) identified that having a person with a disability in a teaching role - recognised as experts in their field - contributed more to developing positive attitudes towards people with disabilities than exposure to disability in other scenarios. This resonated with the teacher tutor with a disability as she would be facilitating extensively reflective assessment on workplace based learnings for this work-integrated learning subject, therefore there was the potential to see what learnings these students may gain regarding disability through their engagement with a tutor with quadriplegia mixed type cerebral palsy.

This article will focus on the 'additional' or 'alternate' learnings derived from the interaction with the tutor with a disability. The uptake of content and discussion of technologies for people with a disability to teach will be the topic of another paper. The research question guiding this component of the study was thus: What are the perceptions and additional / alternate learnings achieved by university students engaging with a tutor with quadriplegia mixed type cerebral palsy? 


\section{Method}

This research incorporated three different data sources; the handwritten student comments from a university-administered anonymous teaching evaluation for the tutor with a disability at the end of her first teaching semester undertaken in May 2011, and two identical purpose-designed online surveys administered at the end of semester in November 2011 and June 2012. The two online surveys collected both quantitative data, with students being able to tick the most appropriate response and qualitative data, with students able to contribute extended responses to a number of questions.

As the subject coordinator and tutor were a focus of discussion in data collection for this research, and are the authors of this paper, the purpose-designed online survey was facilitated by an independent research assistant. While the data collected was anonymous, this research assistant removed any possible identifying elements in student responses to ensure anonymity.

A total of 41 students were enrolled in Autumn 2011 semester and 31 of these students completed the May 2011 teaching evaluation survey. Some 61 students were enrolled in Spring 2011 semester and 15 responded to the online survey. Finally 60 students were enrolled in Autumn 2012 semester and seven responded to the online survey. Considering the two online surveys together there was an overall response rate of $18 \%$. The lower participation in the Autumn 2012 survey compared to Spring 2011 maybe somewhat explained by a technical issue where the embedded link to the survey (distributed by the University’s Student Online Services system) did not click straight through to the survey therefore students needed to cut and paste the link. This was not an issue in the Spring 2011 data collection. 
Please note that, in the findings, students from the Autumn 2011 cohort are referred to as “A11-\#' where the hash represents the number allocated to a participant. Students from the Spring 2011 cohort are referred to as “S11-\#' and those from Autumn 2012 as 'A12 - \#'.

The responses collected from each of the data sources were first analysed separately to see if there were any identifiable patterns or themes emerging from the students pertaining to a particular semester. Once this was undertaken, the qualitative data (which comprised the focus of this paper) did not appear to be particularly distinct between semesters and therefore the data collected from the multiple sources was then considered as a whole. Responses were manually coded into themes by the principal researcher firstly by the topic explored in each question but then, more importantly, into emerging sub-themes which could incorporate responses from various questions from the different data collection tools. The emergent themes related to student perceptions of the tutor with a disability, the learning experience and additional / alternate learnings are the focus of this paper's findings and discussion.

It is important to note that the analysis recognises the inherent challenges of seeking out open and honest responses on disability; a potentially challenging, emotional, taboo or completely normal topic of discussion depending on the individual research participant and their experience with disability / people with a disability. There is, therefore, analysis of what is said, what is omitted, but also of the paradigms reflected in the perspectives presented.

\section{Findings}

The physical encounter between students and the tutor with a disability in the first lecture was the initial potential point for engagement in 'other' learning related to disability. When asked about how they felt when they first realised their tutor had a disability, responses ranged from 'shock' to 'feeling good'. 
Some students found meeting the tutor at the first lecture confronting. One student wrote "I was surprised, purely because you don't expect people to have a disability and I have found that people often forewarn others of disabilities. I thought it was great that Suzanne was able to be our tutor." [S11-14] A fellow student wrote "I was shocked at first because I had no idea she had a disability - it wasn't publicised or mentioned.” [A12-2] These two comments raise an interesting point around people's expectations of disability and protocols which may, or may not, be required in a teaching role. For example, some students felt that solely having a physical presence in the room, with the lecturer normalising the disability by involving the tutor in discussions albeit via eye contact and movement, was unusual because there was no 'forewarning'.

A number of students immediate response regarding her opportunity to work was positive, with one student saying it "Made me feel good about UOW [the University of Wollongong] giving everyone a chance to work" [S11-1]. The fact that a person with a disability was engaged in a teaching role, an intellectually respected role, implied to one student that she was offered more than the opportunity to work, instead, this tutor had a career and the student "felt glad that she [the tutor] has been able to have a career in her situation...” [S11-7]

Each of these comments suggests that the students were considering the tutor's hiring in a broader institutional context. There was a positive critique of the educational institution for "giving everyone a chance"” and this hints at an overall perception that the university, by welcoming diversity, is a place of belonging for everyone.

Overall, both the 'shock' and 'feel good' responses suggest that most students were unaccustomed to seeing disability in their educational setting but, more broadly, in a workplace setting. Simply seeing this began to open their minds to the possibilities of what people from a diverse range of backgrounds and experiences can achieve. 
Indeed, from their understanding of disability, quite a few students were surprised by the tutor's abilities. Perhaps in contrast to original expectations, one student commented " $I$ was impressed by her abilities. I have no problem with her disability and I found that she really understood me.” [S11-4] Another wrote "Her feedback had always been great, and she's clearly a very intelligent woman.” [S11-14] For other students, the interaction with someone with a disability sparked their curiosity in how work can get done and prompted one student to write "I was interested in learning more about her, how she does her job, and her motivation to get where she is, as that must have been a challenging job.” [A12-3] It is important to mention that there was a minority of students who were more generally informed and comfortable with disability and commented that seeing the tutor with a disability was not a surprise. One student wrote "I had no predominant feelings towards the discovery." [S118] And another "Not concerned at all. If the tutor was unable to perform her duty, she would not have been hired by the university. I hold this thought to be true when I consider that the world's most brilliant mind is held by a man with a disability." [A12-6] In this case our tutor was being compared to well-known physicist Professor Stephen Hawking who, unlike the tutor, has motor neurone disease but does use a sophisticated wheel chair and voice software so there are physical similarities between the physical equipment used by these two people. This last comment highlights the importance of role models with a disability in academia to create a reference point in the mind of students. The assumption of high intelligence interestingly contrasts with those who were, as mentioned earlier, surprised by ability.

This does raise an interesting point that the credibility of the teacher, a point of consideration for all educators, may be particularly important in this scenario because of the predominant focus of students, at the beginning, on 'disability' rather than 'ability'. One student commented that they had no concerns regarding having a tutor with a disability " $a$ s [the lecturer] had given her such a good wrap.” [S11-2] The student implies here that the 
lecturer's attitudes and behaviours were used by students as a measure of the competence and capabilities of the tutor. Setting the scene by having a face-to-face interaction with the tutor in the first lecture, accompanied by the lecturer outlining the practicalities of how to interact with the person with a disability, reaffirming her ability and addressing the concerns of students does seem to have been an effective strategy in setting up the tutor - student interaction to be continued online.

This also raises the importance of the digital story played in the first lecture which was created by the tutor to discuss her assessment expectations and give a brief insight into her academic background (including photos at graduation from a Masters in Commerce). A digital story, in this context, was a narrated series of images presenting details both on the tutor and her perspective on assessments. The lecturer suggested the creation of a digital story as it had the opportunity to have images but also the tutor's voice through simulation software. The goal of the digital story was to explain how the tutor and class would interact regarding assessment without overemphasizing the ‘disability' in the tutor's role as an educator.

The digital story was found to help students better understand assessment expectations with comments such as "Prepared me for the internship." [S11-4] Some students were inspired and encouraged "It was a good lesson in empathising with other people's situations and it was inspiring to see Suzanne achieving so much.” [S11-7] Others addressed the basic logistics of how the tutor student interaction would occur "It answered some of the questions I had about her, and motivated me to do my best, as if she could overcome those challenges, then I can do something like she has done and I do not even face any disabilities." [A12-3] Another wrote "I wondered about how submission and feedback for assignments was to occur but then felt comfortable once I understood the process." [S1116] One student appeared to have a rich learning experience derived from the digital story 
writing "It just showed me that limit is generally an intangible element which we can overcome and that I would have no problem with the subject as it progressed." [A12-6] This student achieved a new perspective on limitations and an assurance that students were 'in safe hands'. Yet another student felt the digital story motivated them and wrote that it "Encouraged and motivated me to work harder, especially after she explained the studies she has undertaken. Made me think, I shouldn't have any excuses to being lazy.” [A12-7] The personal connection created by the digital story helped the student to reflect on their personal life circumstances and assure them about the assessment expectations.

Once the semester was underway the interaction was predominantly online. Many students commented on the speed of the tutor's feedback to students by commenting "She was probably faster in replying to e-log entries than other tutors I have had.” [S11-1] Another student commented "The feedback given immediately by the facilitators" [A11-1] as important to their positive experience. Other students touched on the idea that the tutor's disability gave her a unique perspective and "she was more like a mentor rather than a tutor." [S11-4] Perhaps due to her personal circumstances, the tutor "came across as much more understanding and willing to help and was also nearly always contactable which was great! I don't think Suzanne having a disability hindered my experience at all, indeed having someone so understanding (disabled or otherwise) greatly enhanced my experience." [S1116] This last comment illustrates the perceived value that this different perspective had in a student's learning experience and the tutor's genuine care for the students.

In the online environment some students continued to be inspired by the tutor when reflecting on her disability as they prepared assessments for her. For example "It made me think more about how lucky I am to be able to do the things I can. I also felt guilty for getting sick of sitting at a desk all day. I thought more about how grateful I was to have the opportunity to do the internship and be able to learn from someone in her position.” [A12-3] 
Other students wrote that after a while the disability made no difference, it had no effect on their learning or interaction with the tutor. One student wrote "After the first couple of interactions she convinced me that she was capable of the task.” [A12-5] And another even commented that it was such a normal tutor student interaction that "I forgot that she had a disability until I saw her again at the final lecture as our interaction was no different to what would have occurred with any other tutor.” [S11-16]

Some students did, however, hint that they had to go through some actual adjustment of behaviour in developing their relationship with their tutor: "I called her not realising that this was not as practical as emailing - emailing was no problem though so I stuck with that and she was always happy to reply with advice and assistance.” [S11-16] Of course, learning how to adapt communication techniques is a valuable skill for any young professional about to enter the workforce and is not limited to working with people with a disability.

A limited number of students had a profound learning experience from this student tutor interaction and suggested that the experience would be taken forward into their working life with one student writing: "I think working with someone with a disability has made me more aware of the challenges faced by people with a disability as well as breaking down a barrier between people with a disability and those without when considering people to work with.” [S11-6] Having a tutor with a disability exposes students to diversity, acceptance and opens their thinking with regard to how people with a disability might be able to be involved in their work and career - an ideal outcome linking learning about diversity to the student's work-integrated learning experience.

The only negative comment received on the tutor's participation in teaching came from one student who wrote "I never met her. I was unsure the assignment was returned. I am very unsure how she would teach a standard tute?”[A11-2] As the student never met the tutor it is clear that they did not attend the lectures and therefore had a very confused 
perspective on the situation. This illustrates the importance of scaffolding and the physical presence of the tutor in the classroom (along with the student's attendance) in taking full advantage of potential learnings.

\section{Discussion}

Even in academia, with its growing social theory associated with marginalised groups, people with a disability are underrepresented. While gender, race and culture are explored, "The disabled human body is one of the last 'body frontiers' to be addressed in education." (Anderson 2006, 77). This is despite the fact that, according the Anderson, disability is the world's largest multicultural minority and many people - more than just those born with a disability - will become disabled temporarily or permanently in their lifetime including teachers at universities (Anderson 2006).

Beyond the usual perspective that disability is something to be accommodated in the classroom; there is the positive potential for other learning associated with the interaction between able-bodied people and people with a disability in the classroom. Pritchard suggests that teachers with a disability are not only capable of delivering content for student learning but teach students about disability (Pritchard 2010). Indeed, reflecting upon Gordon and Rosenblum's work in 2001 in this current context, it challenges the dichotomy of 'defective' versus 'normal' with students seeing the abilities of the teacher through the interaction.

It is clear from students’ initial reactions that they were unfamiliar with interacting with someone with a disability as a teacher in an academic setting. Some students expected to be 'warned' about disability and felt shocked. Pritchard explains that "There may be 'discomfort' (for ourselves as teachers with disability and undoubtedly for others) associated with being visible, but the alternative only ensures continued exclusion from all levels of education and does nothing to challenge the exclusionary boundaries of the current dominant academic culture and ableist paradigm.” (Pritchard 2010, 47). Once the students 
acclimatised to this new experience they clearly identified benefits both for the tutor and themselves as learners.

The physical presence of the tutor helped “...challenge the animosity of dominant cultural beliefs around disability as analogous with passivity or non-achieving, and provide a source of resistance, solace and resolution for students they teach.” (Pritchard 2010, 43). Most students were surprised by the competency of the tutor but, beyond this, there was a recognition that she had taken students on an unexpected learning journey which led to a reevaluation of their perspective on the abilities of people living with a disability. Kumari Campbell explains that disability is conceptually 'inherently negative' in society so this “disallows the pedagogical imagination to consider disabled teachers as knowers" (Campbell 2001 cited in Kumari Campbell 2009, 716).

The physical presence of the tutor in the classroom was important, not just as a symbol of advocacy for such opportunities, but also vital to creating the 'alternative' learning experience. Students who attended the lectures understood the tutor's context and demonstrated disability-derived learnings compared to the student who purely interacted with her online. As Kumari Campbell explains “... we cannot 'know' existence without being rooted to our bodies.” (Kumari Campbell 2009, 715). Much of what students learned was derived from their understanding that they were interacting with someone with different life experience shaped, in many ways, by an unusual physical body. Students felt the tutor’s unique perspective flavoured her feedback - she mentored rather than taught, she encouraged students to overcome challenges and offered problem-solving alternatives that the ablebodied students who, perhaps because they aren’t challenged with problem-solving in negotiating their way through every day, were unable to find on their own. As per Shannon et al. (2009) and then Hayashi and May (2011), the legacy of an interaction with a teacher 
with a disability was - in most cases - a more positive attitude in general towards people with disabilities.

Students felt empowered to meet challenges of their internships, inspired by the achievements of their tutor with a disability as perceived in the physical classroom. Kumari Campbell states that, for students with and without a disability, seeing someone with a disability in a teaching role "connotes possibility - a belief that says, "if you can then I could too’...” (Kumari Campbell 2009, 720). According to Pritchard: “For marginalised and minority group students the disabled teacher can represent optimism that obstacles can be met and challenged, if not overcome.” (Pritchard 2010, 44 - 45). However, Connor and Baglieri (2009) comment that perceptions about people with a disability overcoming diversity could be about the normalisation of disability in an ableist society resonates here too with some student perhaps achieving awareness of disability without the deeper understanding of the "...richness and complexity of actual lives that are described or claimed as disabled." $(2009,348)$

At the same time, from an advocacy point of view, choosing to have a physical presence in the classroom was an attempt to acknowledge that "If we (people with disability) are not 'seen' within the university environment we are not counted ... in anything. We may presently be acknowledged, even mentored and respected by a handful of not-disabled academics, but the systemic issues of discrimination and oppression can go unchecked unless we increase our visible presence” (Pritchard 2010, 46). The learning outcome for students makes the physical presence of the tutor with a disability in the classroom pedagogically justified but the associated learnings of academic colleagues surrounding this practice may be even more powerful. Indeed, this article is aimed at building this broader awareness of disability in academia and the potential for harnessing people with diverse backgrounds and experiences to engage students in a rich learning experience which informs them for life. The 
online environment, in contrast, shifted the focus from disability and onto curriculum-centred learning. Buckley explains “Online teaching bypasses the logistical inadequacies of physical classrooms and avoids the possibility of students' forming impressions of me based on what they may perceive as gracelessness in my physical presence” (Buckley 1997, 182). Once removed from a face-to-face interaction with disability, some students 'forgot' about the tutor's disability. Others, however, reflected on the tutor's disability as they submitted tasks but it did not cause the same emotional disquiet as in the physical classroom environment even though behind the scenes the tutor was putting in considerable additional effort to complete work. It suggests that, logistically, the online environment provides an important common ground for curriculum-centred learning. This concept will be explored in another paper.

Overall, it is evident that that students learned important lessons additional to the curriculum by having an experience with a tutor with a disability. As Anderson explains: "Pedagogy is also shaped by our life experiences. Teachers with disabilities offer knowledge through their bodies and experiences that isn't usually part of the curriculum. Disabled teachers embody pedagogies of justice, interdependence, and respect for differences." (Anderson 2006, 368). Having a tutor with a disability initially challenged students but, as they progressed through the semester, many were able to value the distinct perspective derived from life with a disability and some reflected positively on the institution for supporting this initiative

\section{Conclusion}

From the interaction between university students and a tutor with quadriplegia mixed type cerebral palsy it was clear that, beyond the curriculum content, students learned that teachers with a disability can have a place in tertiary education and, as a consequence, a wide group of people belong in this environment in spite of any marginalisation they may 
personally face in the broader community. Students learned that having a disability does not automatically equate to a reduced capacity to complete tasks or achieve work objectives. Indeed the tutor routinely exceeded expectations. Students learned that diversity could bring a different, but valuable, perspective. When they were mentored by someone with a disability, the feedback and opinions motivated and inspired them to achieve more in their life. By observing the challenges faced by their tutor, they were themselves challenged to take full advantage of their faculties. Not only was it a positive life lesson, there were immediate educational benefits as students stepped up to embrace their work-integrated learning internship experience out in industry.

Students who achieved the deepest learning experience from the student-tutor interaction were able to imagine workplace scenarios where they could envisage a person with a disability being engaged This, of course, is enormously personally rewarding for the tutor, a passionate advocate for people with a disability achieving greater work opportunities, but this also demonstrated a strong synergy between the work-integrated learning and the 'alternative' learnings promoted via the interaction with disability.

Finally, students who did not appear to have 'other' learning from the experience either had adjusted perspectives based on extensive personal experience with disability or did not engage with the tutor in a meaningful way and therefore did not have an opportunity for additional learning.

In conclusion, it was possible to see that engaging people with a disability in teaching can create opportunities both for people with a disability but also less tangible, less curriculum-centred, learning for students. In the words of one student "I was happy to see that [our tutor] was able to contribute as I cannot image the challenges that she must face on a day to day basis. But here the university has been able to give her the opportunity to contribute and make a difference to so many people's lives.” [S11-6] This statement 
confirmed for the teaching team that the tutor had both contributed and made a difference to at least this student's learning.

It is recommended that future research focus on identifying the most effective blended learning techniques to maximise student learning around disability. Also it is important to recognise that, according to Pritchard, we do not see people with disabilities in the classroom because “deeply held socio-cultural attitudes also prevent disabled people accessing and attaining basic and later, higher levels of academic achievement” (Pritchard 2010, 43). A further study is planned to find out about how universities can integrate disability into academic teaching practice by overcoming earlier barriers and ensuring that people with a disability achieve the required education for undertaking this work.

At the same time, there is a risk that disability may become too strong a focus in the educational setting, so one of the challenges ahead is how to embrace the unique perspective which is informed by a disability while, at the same time, avoiding "the academic's teaching and research perspectives being seen solely through the lens of the disability experience to the exclusion of other positionalities" (Kumari Campbell 2009, 719). That is to say, to ensure that people living with a disability have the opportunity to teach but that teaching is not defined by the disability, and that career progress is self-determined. Researching how to maximise student learning without entirely being defined by a disability is yet another potential area for further study.

\section{References}

Anderson, R. C. 2006. Teaching (with) Disability: Pedagogies of Lived Experience. Review of Education. Pedagogy, and Cultural Studies 28:367-379.

Buckley, J. 1997. The Invisible Audience and the Disembodied Voice: Online Teaching and the loss of Body Image. Computers and Composition 14:179-187.

Centre for Developmental Disability Health Victoria. 2005. Cerebral Palsy. Notting Hill, Victoria, Australia: Centre for Developmental Disability Health Victoria. 
Connor, D. and Baglieri, S. 2009. Tipping the scales: Disability studies asks: "How much diversity can you take?” In Diversity and Multiculturalism: A reader, 341-359. New York: Peter Lang.

Gordon, B. and Rosenblum, K. 2001. Bringing disability into the sociological frame: A comparison of disability with race, sex, and sexual orientation statuses. Disability and Society 16:5-19.

Hayashi, R. and May, G. 2011. The effect of exposure to a professor with a visable disability on students' attitudes toward disabilities. Journal of Social Work in Disability and Rehabilitation 10:36-48.

Kumari Campbell, F.A. 2009. Having a career in disability studies without even becoming disabled! The strains of the disabled teaching body. International Journal of Inclusive Education 13:713-725.

Pritchard, G. 2010. Disabled People as Culturally Relevant Teachers. Journal of Social Inclusion 1 (1):43-51.

Shannon, C., Schoen, B. and Tansey, T. 2009. The effect of contact, context, and social power on undergraduate attitudes towards persons with disabilities. Journal of Rehabilitation 75(4):11-18. 